\title{
SENHORA DOS AFOGADOS: ITINERÁRIO BALDEANTE DE UM MITO
}

Carlinda Fragale Pate Nuñez

USU

Nelson Rodrigues associa-se aos recriadores de Electra no teatro contemporâneo, instilando na problemática universal e atemporal do mito aspectos de uma brasilidade não-folclórica, representada pelo mar imenso que determina a configuração geográfica do Brasil e se infiltra no roteiro dramático, na caracterização das personagens, na ambientação da trama e até mesmo na concepção de Senhora dos afogados (SA) como espetáculo.

Esta peça se destaca no conjunto de obras míticas do autor, tanto por ensejar a cadeia deformante que leva a O'Neill (Mourning becomes Electra, MBE) e deste a Ésquilo (Oréstia), quanto por permitir-se a reformulação de ambos os textos de referência.

Legitimam-se, assim, algumas consideraçōes iniciais sobre MBE. 0 argumento desta trilogia se inicia nos subúrbios de uma das cidades da Nova Inglaterra (a parte mais puritana dos Estados Unidos), logo após o fim da guerra de Secessão. A capitulação do general Lee, a 09/04/1865, funciona como referente histórico para os fracassos e convulsões deslocados do campo de batalha para 0 contexto familiar do protagonista de O'Neill, o Gal. Ezra Mannon.

Associa-se este ao Agamemnon da lenda grega, tanto pelo aspecto bélico, quanto pela sonoridade de seu nome, remissivo a "man" / "Mann" (do inglês e do alemão, respectivamente), mas também alusivo à condição mítica do super-homem, do NO(N)-MAN, ou seja, do deus oculto sob a condição todo-poderosa do militar.

Em Nelson Rodrigues, o nome da famflia Drummond confirma, também pela semelhança fônica, o reacionamento da maldição familiar, instituindo, todavia, como patrono das vicissitudes domésticas, um representante do poder político, 0 Juiz Misael Drummond, em vias de ser nomeado ministro de Estado.

A rainha Clitemnestra é representada, em MBE, por Christine Mannon, associada à primeira pelo adultério com um tio do marido e por tramar o assassinato deste. Em relação à Eduarda, de $\mathbf{S A}$, a virilidade de suas ancestrais dramatúrgicas vem consignada na forma feminina do nome de origem germânica. Significando, etimologicamente, "aquela que guarda riquezas", ou "a protetora de heranças", Eduarda rememora a tamia (esposa) grega, apesar de a personagem brasileira ter expressos na beleza fisica, na juventude duradoura e nos dotes discretamente sedutores seus maiores bens. As três esposas infiéis mais se identificam, todavia, por serem consideradas estrangeiras.

Desviados de Ésquilo, que consigna, nas Coéforas, o assassinato de Clitemnnestra por seu filho, O'Neill concebe, na segunda peça de sua trilogia, a mãe suicida, enquanto Nelson Rodrigues - 0 que mais se distancia do roteiro tradicional inverte 0 programa dramático da personagem, fazendo-a vítima do marido, que permanece vivo até a última cena da tragédia brasileira.

Ao contrário do mito grego, Eduarda não detém a marcialidade de sua congênere Clitemnestra. 0 deslocamento do instrumento sacrificial para 0 marido, 
que 0 utiliza por duas vezes, não significa a transferência, para Misael, da astúcia e da habilidade representadas por sua detentora na saga antiga.

Em oposição a isto, é o uso grosseiro, animalesco e a serviço da barbárie que se manifesta nos atos de degolamento e de amputação meramente impulsivos, destituídos das conotações religiosas que se fazem notar na versão grega do mito.

Tal sorte de mudança nas motivaçōes do novo drama e no encaminhamento das ações decorre da transformação do foco problemático do discurso, centrado, tanto em O'Neill quanto em Nelson Rodrigues, nas forças primitivas do comportamento humano.

Ainda em relação ao papel da esposa infiel, há aspectos que merecem ser focalizados. Ésquilo concebeu Clitemnestra a partir de dois atributos básicos - a astúcia e o poder de persuasão.

O'Neill acentua, em Christine, o senso estratégico, dando-lhe condições de acionar, no momento adequado, o plano de envenenamento do marido. Mas a calculabilidade não é o seu forte, pois que, vencida pelo impacto homicida, desmaia e permite que se torne conhecido 0 instrumento (veneno) de incriminação.

Nelson Rodrigues retém a fórmula o'neilliana- (em vez de machado, veneno), usando-a, porém, para blefar com as próprias expectativas das demais personagens e do público. Esvaziadas as expectativas iniciais de envenenamento do marido pela esposa, torna-se o veneno inócuo, e Eduarda, que desarma a vigilância de todos, legítima detentora das propriedades letais do veneno.

A motivação deste ingrediente dramático está no discurso esquiliano, onde se encontram numerosas referências a Clitemnestra como manipuladora de uma farmacopéia aplicada ao cumprimento de seus interesses nefastos.

Com finura, Nelson Rodrigues converte o mentiroso comprometimento cardíaco presente na tragédia dos Mannon em diagnóstico autêntico da morte de Misael Drummond. Só que 0 ataque mortifero que fecha 0 drama brasileiro é expressão das cardiopatias simbólicas destes prescritos para 0 amor.

0 Orestes norte-americano rememora a personagem grega pelo próprio nome, Orin, mas, fundamentalmente, por salientar a ligação entre mãe e filho, nos termos em que o concebeu Ésquilo.

Os ciúmes que Orin sente ao ser comunicado de que a mãe tem um amante supera a dor por imaginá-la assassina de seu pai. Os desejos incestuosos de Orin pela mãe e, mais tarde, pela própria Irmã, compõem o perfil de seu preposto, na cena rodriguiana, Paulo.

Este é, efetivamente, "paulus", "pequeno" perante a imagem idealizada da mãe e em função da necessidade de reunir-se às duas irmãs afogadas, mergulhando no mesmo mar que as fez morrer.

Nem Orin, nem Paulo se prontificam ao ato justiceiro de Orestes. equivalem-se pela fragilidade perante suas irmãs e por não sujarem as mãos com 0 derramamento de sangue materno. Ambos assumem, sim, liquidar 0 amante de suas mães.

0 drama de Orin se prolonga da segunda para a terceira peça da trilogia o'neilliana. Justamente na última parte da obra, após a morte dos amantes, aparecem as imagens que mais intensamente influenciaram Nelson Rodrigues na reelaboração do roteiro mítico de sua Electra.

0 discurso da última peça da trilogia de O'Neill se abre pelo retorno de Orin e Lavínia à casa, depois de uma viagem que se poderia considerar de 
purificação (como a que tevou Orestes a Delfos) pelas ilhas do Sul. Nestas paragens idilicas, Lavínia tem amantes que servem de base para a construção da personagem rodriguiana, o Noivo. Os carismas da vilegiatura maritima experimentados pelas personagens de 0 'Neill constituem o elemento provocador da concepção rodriguiana do mito.

Enquanto as ilhas do sul funcionam como espaço geográfico necessário para 0 encaminhamento dos fatos, na trilogia norte-americana, para Senhora dos alogados a ilha é um espaço imaginado que inspira ações e alimenta $0 \pi \alpha \theta 0 s$ trágico. A ilha desta peça ninguém aporta. Ela é emissária de visitantes que estão sempre a relembrar a pertença das personagens a um mundo determinado pela simbólica das águas.

Há todo um movimento contrário àquele descrito pela trilogia de 0 'Neill, a partir mesmo da idéia de que, neste, personagens se locomovem e têm, nas ilhas, um ponto intermediário do périplo que se inicia e termina na mansão dos Mannon. Em vez disto, as personagens de Nelson Rodrigues sāo estáticas. Como rochedos abandonados à beira-mar, não se deslocam do seu porto-seguro. A casa vive guardada pelos retratos dos antepassados, reduplicada pelo espelho gigantesco da última cena e ancorada na "cama hereditária".

A única quebra deste esquema de rígida configuração espacial ocorre com o deslocamento da ação para o Café do cais, sucursal da ilha imaginária e vestíbulo para os postulantes à Viagem.

A ação dramática é deflagrada, aliás, pela coincidência entre a "partida" de Clarinha e o "retorno" da prostituta, há dezenove anos assassinada. A superposição dos acontecimentos condiciona a estrutura dúplice de todo 0 desenvolvimento dramático, que tem no Noivo o seu representante mais claro.

Esta personagem reúne os papéis do Orestes e do Egisto gregos. Relaciona-se com o último, por valer-se do noivado com Moema para alcançar 0 objetivo de vingar-se não da mãe, como reza o mito tradicional, mas do pai que a assassinara. Como meio-irmão de Moema, que só se dá a reconhecer no momento adequado e vive 0 drama da fixação na imagem materna, associa-se a Orestes.

A partida cromossomática da personagem, certamente, se encontra no Adam Brant de O'Neill, o capitāo da Marinha norte-americana que se aproxima de Lavínia, para preservar o adultério com Christine. Sem nome, nem sobrenome, 0 Noivo utiliza como arma para a sua vingança a sexualidade de todos os integrantes da familia Drummond, astúcia que não deixa de estar representada nos simbolismos do nome Adam e do sobrenome Brant (do inglês, "brant", ave selvagem, ganso) de que é, obliqüamente, tributário.

A mesma anterioridade simbólica se encontra na reatualização de Electra, seja na figura da Lavínia o'neilliana, seja na Moema de Nelson Rodrigues.

0 desvio que afasta a personagem norte-americana do modelo grego de Electra e simula a aproximaçăo relativa com a heroina latina implica 0 abrandamento inicial do papel conferido a Lavínia, como a destituf-la de uma memória prévia que The condicionasse o programa dramático. Em decorrência disto, a personagem o'neilliana chega ao final da trilogia investida de uma tragicidade que, por si só, a reassocia à Electra mitica, absolutamente so no interior da mansão dos Mannon, com todos os familiares mortos, na sua condição de coéfora a guardar o mausoléu familiar. 
0 mesmo tipo de operação poética enseja a criação de Moema. Não faltou inspiração a Nelson Rodrigues, ao buscar no repertório das tradiçōes indígenas a imagem da mulher que leva aos limites da propria morte a dor de sentir-se rejeitada por seu amado.

São principalmente dois os espaços a que Moema se associa, o mar e o espelho, na verdade, figurações congêneres de uma mesma superfície onde se concentram a vida $\mathrm{e}$ a morte, a identidade $\mathrm{e}$ a diferenç̧a, 0 dentro $\mathrm{e} o$ fora, 0 aquém e 0 além, sempre reportando a idéia de profundidade.

De fato, a regra de concepção dramática adotada em SA é a da reduplicação. Não arbitrariamente, a tragédia reduplicada nos infortúnios protagonizados por Moema e pelo Noivo, pela prostituta e por Eduarda ou pelos irmãos que sucessivamente se afogam, reproduz, estruturalmente, o fatílico espelhismo que os caracteriza: Moema tem as mesmas mãos de Eduarda; o Noivo guarda uma indesejada semelhança com o pai; os Drummond integram uma tradição de trezentos anos de fidelidade.

Como a confirmar a soturnidade represada na estrutura nominal (por - efeito de certa nasalidade sobre as vogais fechadas), a figura feminina que se contrapõe à assexuada Paraguaçu dos versos de Santa Rita Durão é exatamente Moema. Trata-se esta, Moema épica, da amante indesejada, capaz de assumir, no extremado da paixão, a fúria da Yara mítica.

Igualmente peremptória, Moema rebate a percepção lirica do mar referida pelo Noivo. A imagem do oceano terrivel, vestigio cático de catástrofes mergulhadas, imensidão movente e sujeita a convulsões coléricas retém as prerrogativas de um saber anterior e universal, com que Moema se identifica.

Confrontada primeiramente com as irmãs, Moema se investe do fascínio dos reflexơs, na dimensão do brilho estelar contido no mito de Electra. Estes dois códigos simbólicos, associados na protagonista de SA, ratificam-lhe a vacuidade da vida, irresolvida pelo afogamento das irmãs ou pela morte da mãe.

Cumprem-se, na protagonista, os prodigios vaticinados pela forma nominal "mo-ema", supino de "mo-em", ou "mba-em", que signi- fica "fazer vácuo", "fazer exaurir". Moema se traduz, pois, por "a exausta", "a desfalecida", etimológica e poeticamente.

Pelo poder de imantação dos espelhos, a última cena constrói a ìmagem de uma Moema esvaziada de si mesma, à mercê de uma identificação com a mãe que apenas exteriormente se comprovava pela semelhaniça absurda das mãos. De fato, o gesto maternal que descreve ao embalar o pai morto dimensiona as pretensōes mais recônditas de Moema - não só colocar-se no lugar da mãe para o pai, mas fazer-se, perante ele, da mãe que ela idealiza.

Através do espelho que integra o último Ato, recupera-se a idéia de que não há criação sem deformaçăo. Não por outra razăo, a imagem que ele reflete não é a de Moema, mas a de Éduarda mutilada, como a sintetizar, poeticamente, 0 destino do próprio texto: este nunca é totalmente outro, mas o outro do mesmo, representado em sua cárie, falência e incompletude. Se assim não fosse, não se encaminharia o drama para o imbricamento do mundo dos vivos e dos mortos, do passado com o presente, das personagens de fora (cais) com as personagens de dentro (casa), da realidade e do mito.

A própria estrutura do texto rodriguiano se rende à estruturação da trilogia esquiliana, reproduzindo o mesmo roteiro de ação que obedecem as três 
peças gregas.Resgatar efeitos artisticos bem-sucedidos, onde quer que eles apareçam, parece ter sido a regra de criação seguida por Nelson Rodrigues. Admirável é que ela convenha tão adequadamente a SA quanto à teoria dos reflexos que nela se inscreve.

BIBLIOGRAFIA

ALEXANDER, S. Space, time and deity. New York, DoverPublications, 1966.

BACHELARD, G. A Poética do espaço. Abril Cultural, 1970.

BARTHES, R. "0 Teatro grego". In: 0 obvio e o obtuso. R.J.,Nova Fronteira, 1990.

BELLI, A. The use of Greek mythological themes and characters in twentieth century dramas: four approaches. Michigan, U.M.I.,1965.

BRANDÃo, J. de S. Mitologia grega / Vol.I. Petrópolis, Vozes, 1986. . Dicionário m/tico-etimologico. Petrópolis, Vozes, 1991.

BURIAN, J. M. A Study of twentieth-century adaptations of the Greek Atreidae dramas. Michigan, U.M.I., 1960.

CARDOSO, S. et alii. Os Sentidos da paixăo. R.J., Funarte/Cia.das Letras, 1987.

ChAntraine, P. Dictionnaire éthymologique de la langue grecque. Paris, Klinckstieck, 1983.

COHEN, S. H. The Electra figure in twentieth century american and european drama. Michigan, U.M.I., 1968.

CORRIGAN, R. The "Electra" theme in the history of drama. Michigan, 1955.

CORBIN, A. Saberes e odores: o olfato e o imaginário social nos séculos XVIII e XIX. S.P., Cia. das Letras, 1987.

. O Território do vazio: a praia e o imaginário ocidental. S.P., Cia. das Letras, 1989.

DIRKS, M. D. The tragic herooine in the mythlogical drama. Michigan. U.M.I., 1960.

ELLINGSTON, D. E. The Atreidae: a study of the reinterpretations of the myths by Racine, Goethe, Hofmannsthal and Giraudoux. Michigan, U.M.I., 1974.

GOMES NETO, D. O Indianismo na poesia brasileira: contradiçбes ideológicas. R.J., P.U.C., 1982. Dissertação de Mestrado (Xerox).

GREEN, A. Un oeil en trop: le complexe d' Oedipe dans la tragédie. Paris, Éditions de Minuit, 1969.

JUNG, C. G. \& KERENYI, Ch. Introduction à l' essence de la mythologie. Paris, Payot, 1953.

KIRK, G. S. Myth: its meaning and functions in ancient and other cutltures. Cambridge University Press, 1970. 
LOURAUX, N. Maneiras trágicas de matar uma mulher. R.J., Zahar,1988.

LINS, R. L. $O$ teatro de Nelson Rodrigues: uma realidade em agonia. Rio de Janeiro, Francisco Alves, INL, 1979.

MAGALDI, S. Ne/son Rodrigues: dramaturgia e encenação. SãoPaulo, Perspectiva, 1987.

NUÂEZ, C. F. P. Electra ou uma constelaçăo de sentidos. Rio deJaneiro, U.F.R.J., 1991. Tese de Doutorado (xerox).

OITICICA, R. B. da R. Nelson Rodrigues, o bobo da corte de Médici. R.J., P.U.C., 1988. Dissertação de Mestrado (xerox).

RIBEIRO, M. L. C. da R. Drama, matéria de primeira página: o trânsito da informação em Nelson Rodrigues. R.J., U.F.R.J.,1988. Tese de Doutorado (xerox).

SAMPAIO, T. O Tupi na geografia nacional. Bahia, Seçẫo Gráficada Escola de Aprendizes Artifices, 1928.

SHAW, J. T. "Literary indebtedness and comparative literary studies". In: Comparative literature: method and perspective. U.S.A., Southern Illinois University Press, 1973.

STARR, C.G. The influence of sea power on ancient history. Roma, Bretschneider, 1988.

VERNANT, J.-P. A morte nos olhos - figuração do outro na Grécia antiga: Ártemis e Gorgó. R.J., Zahar, 1988. 